\title{
The Deviation on the Determination of Microbial Biomass Carbon in Biochar Amendment Soil with Fumigation Extraction
}

\author{
Hongguang Cheng ${ }^{1}$, Xinqing Lee ${ }^{1}$, Like Zhang ${ }^{1,2}$, Bin Fang ${ }^{1,2}$ \& Fang Yang ${ }^{1,2}$ \\ ${ }^{1}$ State Key Laboratory of Environmental Geochemistry, Institute of Geochemistry, Chinese Academy of \\ Sciences, Guiyang, Guizhou, China \\ ${ }^{2}$ Graduate School, Chinese Academy of Sciences, Beijing, China \\ Correspondence: Hongguang Cheng, State Key Laboratory of Environmental Geochemistry, Institute of \\ Geochemistry, Guiyang, Guizhou 550002, China. Tel: 86-130-3786-6480. E-mail: \\ Chenghongguang@vip.gyig.ac.cn
}

Received: June 4, 2012 Accepted: June 18, 2012 Online Published: August 8, 2012

doi:10.5539/jas.v4n9p251 URL: http://dx.doi.org/10.5539/jas.v4n9p251

\begin{abstract}
Fumigation extraction (FE) is a well proven method to determine microbial biomass carbon. However, the underestimation is generated when FE method was used to determine the microbial biomass carbon in biochar amendment soil. In this study, the microbial biomass carbon in biochar amendment soil which was added glucose or ultra-pure water was measured with FE. The data showed the dissolved carbon which was adsorbed by the soil was increased with along the amount of added biochar. This result indicated that little effect was present on the determination of microbial biomass carbon in biochar amendment soil with FE. Under the rough assessment, the underestimation of $3 \%$ and $5 \%$ were generated when the amount of biochar was $5 \%$ and $10 \%$ respectively.
\end{abstract}

Keywords: biochar, fumigation extraction, biomass carbon

\section{Introduction}

Soil microbial is living component of soil organic matter other than fauna and plant roots in soil. Although only account for $5 \%$ of organic matter in soil, soil microbial which contains all mass of micro-organism such as bacteria, fungi, protozoa (Jenkinson, 1981) plays a critical role in nutrient cycling and therefore is essential for plant grown (Brookes, 2001; Dalal, 1998). Due to living, soil microorganism could be respond rapidly to subtle changes in soil. So the determination of microbial biomass could be used as a proxy for the subtle changes in soil (Brookes, 2001). Previous studies showed fumigation extraction (FE) is a well proven method to determine microbial biomass (Brookes, Landman, Pruden, \& Jenkinson, 1985; Inubushi, Brookes, \& Jenkinson, 1991; Joergensen, 1996). The principle of FE is to extract the cell contents released from ruptured cell which was killed by chloroform fumigation (Dalal, 1998), then to determine carbon mass in the extraction, and calculate the amount of microbial biomass carbon (MBC) (Martikainen \& Palojärvi, 1990).

Biochar is a carbon-rich product which was made when biomass, such as wood, manure or leaves, was heated in a closed container with little or no available air (Lehmann \& Joseph, 2009). Imposed biochar into agricultural soil is considered to a well method to improve soil quality and stimulate microbial activity (Kuzyakov, Subbotina, Chen, Bogomolova, \& Xu, 2009; Lehmann \& Zech, 2004; Steinbeiss, Gleixner, \& Antonietti, 2009). The main explanation is biochar amendment increased the retention capacity of water and nutrient in soil(Lehmann, 2007; Lehmann, Gaunt, \& Rondon, 2006) because of high cation adsorption of biochar (Liang et al., 2006). Smernik, Lehmann, \& Joseph (2009) reported biochar has a sorption efficiency of 1- to 3-fold larger than soil organic matter and could be as a sorbent of organic compounds. In theory, the adsorption capacity of soil is increasing with along the amount of added biochar (Qiu, Zheng, Zhou, \& Sheng, 2009). Naturally, it is sure that more dissolved carbon was adsorbed by the soil which was amended with the biochar. Herein, the underestimate will be generated when the microbial biomass carbon was determined with FE because the high adsorption capacity of soil will hinder the extraction of dissolved carbon from soil. However, so far it is few to systemic discuss the effect on the determination MBC with FE when biochar was added into soil. Durenkamp, Luo, \& Brookes (2010) published the impact of black carbon addition to soil on the determination of soil microbial biomass by 
fumigation extraction and considered that the extraction efficiency of organic carbon was more affected by black carbon. However, this study mainly focused on the effect of different concentration of the extract reagent $(0.5 \mathrm{M}$ $\& 0.05 \mathrm{M} \mathrm{K}_{2} \mathrm{SO}_{4}$ ). So the objective of this study is to estimate the impact on the determination of $\mathrm{MBC}$ in the different proportion of biochar amendment soil with FE.

\section{Materials and Methods}

\subsection{Experimental Materials}

2.1.1 Soil: Soil was collected from the farmland in Tiankan hamlet, Nanlong village, Kaiyang county, Guiyang , Guizhou Province, southwest China $\left(27^{\circ} 00^{\prime} 39.9^{\prime \prime} \mathrm{N}, 107^{\circ} 02^{\prime} 48.1^{\prime \prime} \mathrm{E}\right)$.

2.1.2 Biochar: Biochar was made from rape straw. After dried at natural conditions, rape straw were cut into small pieces and pulled into the pyrolysis barrels which were roasted in the carbide furnace at the temperatures of $550^{\circ} \mathrm{C}$.

\subsection{Experimental Methods}

Soil was dried in natural conditions, and then sieved with the mesh size of $2 \mathrm{~mm}$. Three treatments were designed: 1) Control: without biochar, 2) Mixed with 5\% Biochar (which means 50g biochar into 1000g soil), 3) Mixed with $10 \%$ Biochar. At first, the soil of all treatments were sterilized to kill all living microbes in soil with the method that all soil were put into the fumigation device and fumigated for 24 hours. Then two different condition experiment were operated (unfumigation and fumigation). In unfumigation, $1 \mathrm{ml}$ ultra-pure water or 1 $\mathrm{ml} 5 \mathrm{~g} / \mathrm{L}$ glucose $(2 \mathrm{mg} \mathrm{C})$ was injected into ecah soil treatment which was installed in a plastic bottles, then 40 $m l \mathrm{k}_{2} \mathrm{SO}_{4}(0.5 M)$ was injected. All bottles were oscillated for $30 \mathrm{~min}$ with an end-over-end shaker at the rate of $35 \mathrm{rev} \mathrm{min}{ }^{-1}$, leached. Finally, the filtrate was determined with $\mathrm{K}_{2} \mathrm{Cr}_{2} \mathrm{O}_{7}-\mathrm{H}_{2} \mathrm{SO}_{4}$ external heating method: $15 \mathrm{ml}$ extract is commingled with $5 \mathrm{ml}$ of $0.08 \mathrm{M} \mathrm{K}_{2} \mathrm{Cr}_{2} \mathrm{O}_{7}-\mathrm{H}_{2} \mathrm{SO}_{4}$ and heated with the temperature of $175^{\circ} \mathrm{C}$ for 30 mins, then titrated with $0.05 \mathrm{M} \mathrm{FeSO}_{4}$. At last, the quantity of carbon was calculated according to the amount of $\mathrm{FeSO}_{4}$ consumed. In fumigation, the similar process were operated, the only difference was that chloroform fumigation was presented for 24 hours before the injection of $\mathrm{k}_{2} \mathrm{SO}_{4}$. All the samples were triplicate. Total soil carbon, nitrogen were measured in PE2400- II type elements analyzer (PerkinElmer, U.S.A.). The soil water content was determined with the method of National Standards (HJ613-2011). All experiments were completed in the institute of geochemistry, state key laboratory of environment.

\section{Results}

\subsection{The Characters of Soil}

Carbon and nitrogen content, $\mathrm{pH}$ values were summarized in Table 1 . Soil water content in all treatments of soil was similar, i.e $14.58 \%, 14.20 \%$ and $14.59 \%$ for control, biochar $5 \%$ and biochar $10 \%$.

Table 1. The $\mathrm{pH}$ value and carbon, nitrogen content of soil and biochar

\begin{tabular}{ccc}
\hline & The test soil & Biochar \\
\hline $\mathrm{pH}$ & 8.00 & 10.29 \\
Carbon content (\%) & 5.56 & 65.87 \\
Nitrogen content (\%) & 0.52 & 1.42 \\
\hline
\end{tabular}

\subsection{The Extracted Carbon}

The extracted carbon was showed in Figure $1 \mathrm{a}, \mathrm{b}$. It was decreased with along the amount of biochar addition. In the injection of ultra-pure water experiment, the extracted carbon was lower $10.9 \%$ and $11.9 \%$ in biochar $5 \%$ and biochar 10\% respectively compared with control (Figure 1.a) ( $p=0.003$ and $p=0.002)$. In the injection of glucose experiment, the similar situation was observed ( $p=0.044$ and $p=0.024$ respectively ), i.e. the extracted carbon in biochar 5\% and biochar $10 \%$ were decreased $2.8 \%$ and $3.3 \%$ respectively (Figure 1.b). In addition, the extracted carbon was higher in the fumigation than that's of in the unfumigation. 

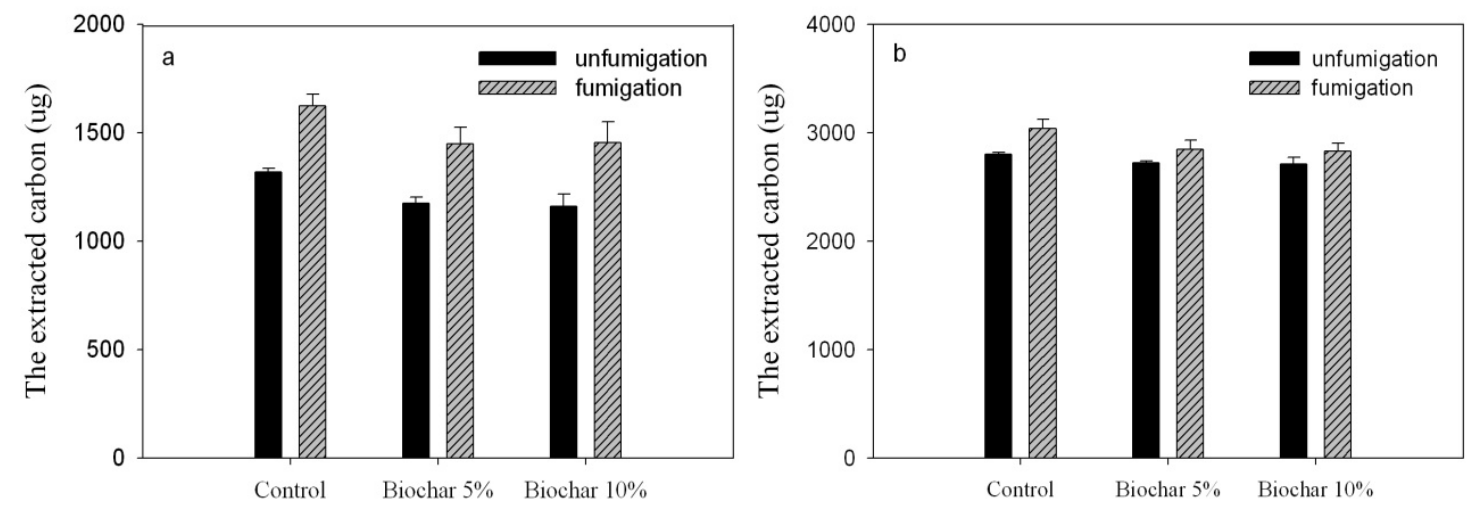

Figure 1. a. Comparison of the extracted carbon between fumigation and unfumigation in ultra-pure water experiment; $b$. Comparison of the extracted carbon between fumigation and unfumigation in glucose experiment

\section{Discussion}

In this study, sterilization is a critical procedure to insure the accuracy of assessment on the impact on the determination of $\mathrm{MBC}$ in biochar amendment soil with FE. It is higher extracted carbon in the fumigation (Figure $1 \mathrm{a}, \mathrm{b}$ ) indicated still a little alive microbe in soil although all of soil were fumigated with chloroform for 24 hours. In this study, in order to eliminate the effect from incomplete sterilization, the adsorbed carbon which was the sum of the extracted carbon in the ultra-pure water experiment and the amount of glucose deducted the extracted carbon in the glucose experiment was used to indicate the quantity of adsorbed dissolved carbon with the hypothesis the alive microbe is same in all of soil. The data showed different trend between unfumiagation and fumigation (Figure $2 \mathrm{a}, \mathrm{b}$ ). It was decreased in the unfumigation with along the amount of biochar and increased in the fumigation. The result was contracted with Jin, Lehmann, \& Thies 's (2008) viewpoint that amended biochar soil has higher adsorption capacity. According to Jin, Lehmann, \& Thies 's (2008) viewpoint, the result should be both increased instead of decreased. Jin, Lehmann, \& Thies 's (2008) studied the adsorption of added DOC in biochar amendment soil and observed it was increased with the time in the beginning. In the study, the extraction was operated once after pure-water or glucose was injected in the unfumigation. The added carbon was extracted by $\mathrm{K}_{2} \mathrm{SO}_{4}$ solution immediately so that the biochar amendment soil was no time to adsorb, the adsorbed carbon was not high in biochar amended soil (Figure 2a). While in the fumigation, the extraction was operated after chloroform fumigation for 24 hours which was enough time for soil to adsorb the added carbon because the adsorption capacity of soil was increased with along the amount of biochar, more added carbon was adsorbed in the biochar amendment soil (Figure 2b).

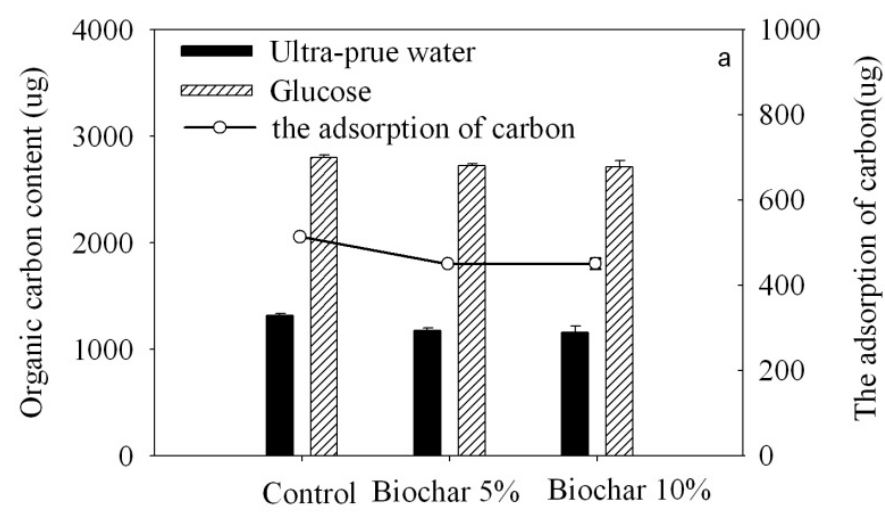




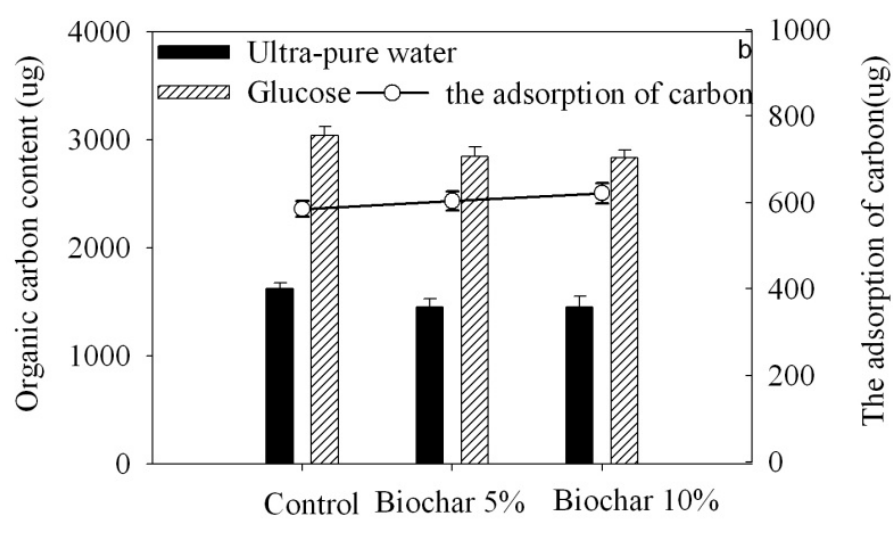

Figure 2. a. the adsorption of carbon in ultra-pure water experiment; $b$. the adsorption of carbon in glucose experiment

At last, the deviation on the determination of MBC in biochar amendment soil with FE was rough evaluated. Compared the extracted carbon between in the fumigation experiment and the unfumigation experiment, the adsorbed carbon was $0.51,0.45$ and $0.45 \mathrm{mg}$ for control, biochar $5 \%$ and biochar $10 \%$ respectively in added ultra-pure water experiment and $0.58,0.60$ and $0.62 \mathrm{mg}$ for control, biochar $5 \%$ and biochar $10 \%$ respectively in added glucose experiment. In study, the adsorbed carbon eliminated the effect of incomplete sterilization with the assumption of the amount of alive micro in all treatment were similar, the adsorbed carbon results showed approximately more $1 \%$ and $2 \%$ of dissolved carbon was adsorbed in biochar $5 \%$ and in biochar $10 \%$ respectively. Obviously, the dissolved carbon from glucose was different with the dissolved carbon of the released content from the ruptured cell and the assumption no effect of alive incomplete sterilization both affect the veracity of this evaluation. Nonetheless, the determination of MBC in the biochar amendment soil with fumigation extraction would cause $3 \%$ and $5 \%$ underestimate for the amount of biochar $5 \%$ and $10 \%$ respectively.

\section{Conclusion}

Though the sterilization was incomplete to cause the estimation to the deviation of biochar addition to soil on the determination of MBC by FE was not accurate, the result still indicated more dissolved carbon was adsorbed by biochar amendment soil which caused underestimation on the determination of $\mathrm{MBC}$ with FE. Under eliminated the effect of alive microbe, the rough assessment was an underestimation of 3\% and $5 \%$ respectively when the mount of biochar was $5 \%$ and $10 \%$.

\section{Acknowledgements}

This research has received financial support from "Strategic Priority Research Program-Climate Change: Carbon Budget and Related Issues" of the Chinese Academy of Sciences, Grant No. XDA05070400, National Natural Science Foundation (40721002 \& 40872212), Agricultural research projects in Guizhou Province (QianKeHe NY [2011] 3079 \& QianKeHe NY [2012] 3019) and the International Scientific and Technological Cooperation Project of Guizhou Province([2012] 7050). All authors herein express their deep thanks.

\section{References}

Brookes, P. (2001). The soil microbial biomass: concept, measurement and applications in soil ecosystem research. Microbes and Environments, 16, 131-140. http://dx.doi.org /10.1264/jsme2.2001.131

Brookes, P. C., Landman, A., Pruden, G., \& Jenkinson, D. S. (1985). Chloroform fumigation and the release of soil nitrogen: a rapid direct extraction method to measure microbial biomass nitrogen in soil. Soil Biology and Biochemistry, 17, 837-842. http://dx.doi.org/10.1016/0038-0717(85)90144-0

Dalal, R. C. (1998). Soil microbial biomass-what do the numbers really mean? Australian Journal of Experimental Agriculture, 38, 649-666. http://dx.doi.org/10.1071/EA97142

Durenkamp, M., Luo, Y., \& Brookes, P. C. (2010). Impact of black carbon addition to soil on the determination of soil microbial biomass by fumigation extraction. Soil Biology and Biochemistry, 42, 2026-2029. http://dx.doi.org/10.1016/j.soilbio.2010.07.016 
Inubushi, K., Brookes, P. C., \& Jenkinson, D. S. (1991). Soil microbial biomass C, N and ninhydrin-N in aerobic and anaerobic soils measured by the fumigation-extraction method. Soil Biology and Biochemistry, 23, 737-741. http://dx.doi.org/10.1016/0038-0717(91)90143-8

Jenkinson, D. S. (1981). Microbial biomass in soil: measurement and turnover. Soil biochemistry, 5, 415-472.

Jin, H., Lehmann, J., \& Thies, J. E. (2008). Soil microbial community response to amending maize soils with maize stover charcoal. In Proceedings of the 2008 International Biochar, Initiative 8-10 September 2009, Newcastle, UK.

Joergensen, R. G. (1996). The fumigation-extraction method to estimate soil microbial biomass: calibration of the kEC value. Soil Biology and Biochemistry, 28, 25-31. http://dx.doi.org/10.1016/0038-0717(95)00101-8

Kuzyakov, Y., Subbotina, I., Chen, H., Bogomolova, I., \& Xu, X. (2009). Black carbon decomposition and incorporation into soil microbial biomass estimated by 14C labeling. Soil Biology and Biochemistry, 41, 210-219. http://dx.doi.org/10.1016/j.soilbio.2008.10.016

Lehmann, J. (2007). A handful of carbon. Nature, 447, 143-144. http://dx.doi.org/10.1038/447143a

Lehmann, J., Gaunt, J., \& Rondon, M. (2006). Bio-char sequestration in terrestrial ecosystems-a review. Mitigation and adaptation strategies for global change, 11, 395-419. http://dx.doi.org/10.1007/s11027-005-9006-5

Lehmann, J., \& Joseph, S. (2009). Biochar for environmental management: science and technology. Earthscan/James \& James.

Lehmann, J., \& Zech, W. (2004). Microbial response to charcoal amendments of highly weathered soils and Amazonian dark earths in central Amazonia-preliminary results. Amazonian Dark Earths. Explorations in Space and Time, 195.

Liang, B. L., Solomon, J., Kinyangi, D., Grossman, J., O'Neill, J., Skjemstad, B., Thies, J. O., Luiz o, J., Petersen, F. J., \& Neves, J. (2006). Black carbon increases cation exchange capacity in soils. Soil Science Society of America Journal, 70, 1719.

Martikainen, P. J., \& Palojärvi, A. (1990). Evaluation of the fumigation-extraction method for the determination of microbial $\mathrm{C}$ and $\mathrm{N}$ in a range of forest soils. Soil Biology and Biochemistry, 22, 797-802. http://dx.doi.org/10.1016/0038-0717(90)90159-W

Qiu, Y., Zheng, Z., Zhou, Z., \& Sheng, G. D. (2009). Effectiveness and mechanisms of dye adsorption on a $\begin{array}{lllll}\text { straw-based } \quad \text { biochar. } & \text { Bioresource }\end{array}$ http://dx.doi.org/10.1016/j.biortech.2009.05.054

Smernik, R. J., Lehmann, J., \& Joseph, S. (2009). Biochar and sorption of organic compounds. Biochar for environmental management. Science and technology, 291-292.

Steinbeiss, S., Gleixner, G., \& Antonietti, M. (2009). Effect of biochar amendment on soil carbon balance and soil microbial activity. Soil Biology and Biochemistry, 41, 1301-1310. http://dx.doi.org/10.1016/j.soilbio.2009.03.016 